\title{
Desempenho agronômico e tecnológico de feijão sob adubação nitrogenada em duas épocas de semeadura
}

\section{Agronomic and technological performance of bean under nitrogen fertilization in two sowing seasons}

\author{
Diogo Cardoso Ferreira \\ Universidade Estadual Paulista \\ E-mail: diogo cferreira@yahoo.com.br \\ OrcID: https://orcid.org/0000-0002-4045-8652
}

Anderson Prates Coelho

Universidade Estadual Paulista

E-mail: anderson 100ssp@hotmail.com

OrcID: https://orcid.org/0000-0003-2472-9704

Rogério Farinelli

Fundação Educacional de Barretos

E-mail: rogerio.farinelli@unifeb.edu.br

OrcID: https://orcid.org/0000-0003-0536-4017

Leandro Borges Lemos

Universidade Estadual Paulista

E-mail: leandro.lemos@unesp.br

OrcID: https://orcid.org/0000-0003-1781-1267

Resumo: No Brasil o feijoeiro é cultivado ao longo de todo o ano, necessitando de diferentes recomendações de manejos agrícolas em cada época para a otimização dos recursos. Objetivou-se avaliar o desempenho agronômico e a qualidade tecnológica dos grãos de cultivares de feijoeiro em função de doses de nitrogênio em cobertura nas safras das águas (verão) e de inverno. Foram instalados dois experimentos em Jaboticabal, $\mathrm{SP}$, sendo um na safra das águas (dezembro a março) e outro na safra de inverno (junho a setembro). Para os dois experimentos, o delineamento experimental foi o de blocos casualizados em esquema de parcelas subdivididas, sendo as parcelas compostas por três cultivares de feijoeiro (Pérola, BRS Pontal e IPR Juriti) e as subparcelas constituídas por cinco doses de nitrogênio em cobertura $\left(0,40,80,120\right.$ e $\left.160 \mathrm{~kg} \mathrm{ha}^{-1} \mathrm{de} \mathrm{N}\right)$, com quatro repetições. Foram avaliados os componentes de produção do feijoeiro, produtividade de grãos, teor de proteína bruta, tempo de cozimento e relação de hidratação. Os dados foram submetidos à análise de variância (Teste F) e, quando significativo, as médias foram comparadas pelo teste de Tukey a $5 \%$ de probabilidade. O desempenho agronômico e tecnológico das cultivares de feijão é superior na safra de inverno. A cultivar IPR Juriti apresenta desempenho agronômico superior às demais cultivares, independentemente da época de cultivo. A recomendação da dose de nitrogênio em cobertura para a safra das águas independe da cultivar (108 $\left.\mathrm{kg} \mathrm{ha}^{-1} \mathrm{de} \mathrm{N}\right)$, enquanto que para a safra de inverno a recomendação é genótipo-dependente.

Palavras-chave: Doses de nitrogênio. Produtividade. Proteína bruta. Safra das águas. Safra de inverno.

Abstract: In Brazil the common bean is cultivated throughout the year, requiring different recommendations of agricultural management in each season for the optimization of resources. The aim of this study was to evaluate the agronomic and technological performance quality of the common bean cultivars as a function of nitrogen rates in the summer and winter harvests. Two experiments were installed in the Jaboticabal, SP, one in the summer harvest (December to March) and the other in the winter harvest (June to September). For the two experiments, the experimental design consisted of randomized blocks, in a subdivided plots scheme, and the plots were composed of three common bean cultivars (Pérola, BRS Pontal and IPR Juriti) and the subplots constituted by five nitrogen rates under topdressing $\left(0,40,80,120\right.$ and $160 \mathrm{~kg} \mathrm{ha}^{-1}$ of $\left.\mathrm{N}\right)$, with four replicates. The production components of common bean, grain yield, crude protein, cooking time and hydration ratio were evaluated. Data were submitted to variance analysis (Test F) and, when significant, the means were compared 
by the Tukey test at $5 \%$ of probability. The agronomic and technological performance of the common bean cultivars is superior in the winter season. The cultivar IPR Juriti presents superior agronomic performance to the other cultivars, independently of the growing season. The nitrogen rate recommendation in topdressing for the summer harvest is cultivar independent $\left(108 \mathrm{~kg} \mathrm{ha}^{-1}\right.$ de $\left.\mathrm{N}\right)$, whereas for the winter crop the recommendation is genotype-dependent.

Keywords: Crude protein. Grain yield. Nitrogen rates. Summer season. Winter season.

Data de recebimento: $11 / 12 / 2019$

Data de aprovação: 08/12/2020

DOI: https://doi.org/10.30612/agrarian.v14i52.10817

\section{Introdução}

O feijão é o terceiro grão mais produzido no Brasil, ficando atrás em área plantada somente da soja e do milho. A área cultivada com feijão no Brasil é de 3,2 milhões de ha, apresentando produtividade média de $1 \mathrm{Mg} \mathrm{ha}^{-1}$ (CONAB, 2018). Durante o ano, o feijão é cultivado em três épocas. A safra das águas compreende a semeadura do feijão entre outubro e dezembro, a safra das secas entre janeiro e março e a safra de inverno com semeadura entre abril e junho. Devido a essa variabilidade de condições que a cultura é submetida durante as safras, especialmente entre a safra das águas e a de inverno, os manejos agrícolas para cada época de plantio devem ser aperfeiçoados para maior otimização dos recursos e renda.

O feijoeiro é uma planta exigente em nutrientes, especialmente o N. Apesar da capacidade de fixar o $\mathrm{N}_{2}$ atmosférico, pela simbiose com bactérias do gênero Rhizobium spp., a quantidade do nutriente suprida por esse processo é insuficiente para o feijoeiro (Hungria et al., 2013). Nesse sentido, verifica-se que a exigência do feijoeiro em nitrogênio é maior que $80 \mathrm{~kg} \mathrm{ha}^{-1}$ de $\mathrm{N}$ para atingir elevadas produtividades (Santana et al., 2010; Guimarães et al., 2017).

O nitrogênio é responsável pelo incremento da área foliar da planta, o que aumenta a eficiência de intercepção da radiação solar, a taxa fotossintética e, consequentemente, a produtividade de grãos (Bernardes et al., 2014). O uso da dose adequada de $\mathrm{N}$ evita o aumento excessivo da área foliar, que pode propiciar auto sombreamento, diminuindo a eficiência fotossintética e a transpiração das plantas (Santos e Fageria, 2007). Além disso, a identificação de cultivares de feijão com maior tolerância ao estresse de nitrogênio e eficiente no uso desse nutriente é outra medida desejável (Leal et al., 2019).

Devido à variabilidade climática e tecnológica que o feijoeiro é cultivado no Brasil durante todo o ano, manejos agrícolas como a adubação nitrogenada, devem ser recomendados com base em estudos para cada época de plantio. Como cultivares de feijão apresentam padrões de resposta distintos entre as safras, como produtividade, tempo de cozimento e teor de proteína dos grãos (Farinelli e Lemos, 2010; Pereira et al., 2014; Perina et al., 2014), e a adubação nitrogenada é um dos principais manejos que altera esses parâmetros, estudos da interação genótipo e doses de nitrogênio no feijoeiro cultivado em diferentes safras tornam-se necessários para indicar o melhor genótipo e a dose de $\mathrm{N}$ em cada situação (Aires et al., 2019).

O objetivo do trabalho foi avaliar o desempenho agronômico e a qualidade tecnológica dos grãos de três cultivares de feijoeiro em função de doses de nitrogênio em cobertura nas safras das águas (verão) e de inverno.

\section{Material e Métodos}

Foram instalados dois experimentos na Faculdade de Ciências Agrárias e Veterinárias, Unesp, Câmpus de Jaboticabal, SP, próximos das coordenadas com latitude de $21^{\circ} 15^{\prime} 22^{\prime \prime} \mathrm{S}$ e longitude de $48^{\circ} 18$ 58 " W. O clima, de acordo com a classificação de Köppen é do tipo Aw, subtropical, com verões quentes e úmidos, e invernos frios e secos, com altitude média de $595 \mathrm{~m}$. Os experimentos foram realizados em duas épocas de cultivo, sendo o primeiro na safra das águas (verão) de 2007/2008 e o segundo, na safra de inverno de 2008.

O solo do experimento da safra das águas foi classificado como LATOSSOLO VERMELHO Distrófico (Andrioli et al. 1999). Antes da instalação do experimento foi realizada a amostragem de solo na camada de 0,00-0,20 m e em seguida análise química para fins de fertilidade (Raij et al., 2001). Os atributos químicos da área foram: $\mathrm{pH}=5,6 ; \mathrm{M} . \mathrm{O} .=15 \mathrm{~g} \mathrm{~kg}^{-1} ; \mathrm{P}_{\text {resina }}=39 \mathrm{mg} \mathrm{dm}{ }^{-3} ; \mathrm{H}+\mathrm{Al}=16 \mathrm{mmol}_{\mathrm{c}} \mathrm{dm}^{-3}, \mathrm{~K}=4,1 \mathrm{mmol}_{\mathrm{c}} \mathrm{dm}^{-3}, \mathrm{Ca}=$ 
$24 \mathrm{mmol}_{\mathrm{c}} \mathrm{dm}^{-3}, \mathrm{Mg}=13 \mathrm{mmol}_{\mathrm{c}} \mathrm{dm}^{-3}, \mathrm{SB}=41,1 \mathrm{mmol}_{\mathrm{C}} \mathrm{dm}^{-3}$ e CTC $=57,1 \mathrm{mmol}_{\mathrm{c}} \mathrm{dm}^{-3}$, respectivamente, e V (saturação por bases) $=72 \%$. De acordo com os resultados da análise química do solo, não houve a necessidade do uso de calcário. A adubação de semeadura foi realizada empregando-se $300 \mathrm{~kg} \mathrm{ha}^{-1}$ do formulado 0-20-20.

A área experimental foi ocupada pela cultura do milho na safra verão de $2006 / 2007$, sendo que após a colheita permaneceu em pousio. Antes da semeadura do feijoeiro, as plantas contidas na área experimental foram dessecadas com glifosato na dose de 3,0 L ha-1 de produto comercial, 22 dias antes da instalação da cultura. A semeadura da safra das águas foi realizada em meados de dezembro de 2007, utilizando-se 12 sementes por metro no sulco, com espaçamento entre linhas de $0,45 \mathrm{~m}$, em condição não irrigada.

O solo da área experimental do experimento da safra de inverno foi do tipo Latossolo Vermelho-escuro eutrófico (Andrioli et al. 1999), sendo que antes da instalação do experimento realizou-se a amostragem de solo na camada de 0,00-0,20 m e posterior análise química para fins de fertilidade do solo (Raij et al., 2001). Os valores dos atributos do solo foram: $\mathrm{pH}=5,7 ; \mathrm{M} . \mathrm{O} .=20 \mathrm{~g} \mathrm{~kg}^{-1} ; \mathrm{P}_{\text {resina }}=59 \mathrm{mg} \mathrm{dm}^{-3} ; \mathrm{H}+\mathrm{Al}=25 \mathrm{mmol}_{\mathrm{c}} \mathrm{dm}^{-3}$, $\mathrm{K}=2,7 \mathrm{mmol}_{\mathrm{c}} \mathrm{dm}^{-3}, \mathrm{Ca}=30 \mathrm{mmol}_{\mathrm{c}} \mathrm{dm}^{-3}, \mathrm{Mg}=7 \mathrm{mmol}_{\mathrm{c}} \mathrm{dm}^{-3}, \mathrm{SB}=39,7 \mathrm{mmol}_{\mathrm{c}} \mathrm{dm}^{-3}$ e CTC $=64,7 \mathrm{mmolc} \mathrm{dm}^{-3}$ ${ }^{3}$, respectivamente, e $\mathrm{V}$ (saturação por bases) $=62 \%$.

De acordo com os resultados da análise química do solo, houve a necessidade do uso de calagem, sendo aplicados $700 \mathrm{~kg} \mathrm{ha}^{-1}$ de calcário dolomítico com PRNT de $90 \%$, visando elevar a saturação de bases a $70 \%$ (Ambrosano et al., 1997). A adubação de semeadura foi realizada levando-se em consideração recomendações técnicas de Ambrosano et al. (1997), empregando-se $300 \mathrm{~kg} \mathrm{ha}^{-1}$ do formulado 0-20-20.

A área experimental foi ocupada pela cultura do milho na safra verão de 2007/2008 e antes da semeadura do feijoeiro, as plantas contidas no local foram dessecadas mecanicamente com glifosato na dose de 3,0 L ha ${ }^{-1}$ de produto comercial. A semeadura da safra de inverno foi realizada em 15 de junho de 2008 , utilizando-se 12 sementes por metro no sulco, com espaçamento entre linhas de 0,45 m. Por necessidade, o feijoeiro da safra de inverno foi irrigado durante todo o ciclo, aplicando-se água para suprir $100 \%$ da necessidade da cultura. A lâmina de água aplicada via irrigação por aspersão convencional foi de $360 \mathrm{~mm}$, suprindo as necessidades hídricas do feijão (Fischer Filho et al., 2014).

Para ambos experimentos, o delineamento experimental utilizado foi o de blocos casualizados, num esquema de parcelas subdivididas, sendo as parcelas compostas por três cultivares de feijoeiro do grupo comercial carioca (Pérola, do tipo II/III, ciclo de 95 dias e porte semi-ereto; BRS Pontal, do tipo II, ciclo de 87 dias e porte semi-prostrado e IPR Juriti, do tipo III, ciclo de 89 dias e porte ereto) e as subparcelas constituídas por cinco doses de nitrogênio $\left(0,40,80,120\right.$ e $160 \mathrm{~kg} \mathrm{ha}^{-1}$ de $\left.\mathrm{N}\right)$, aplicadas em cobertura, em quatro repetições. A aplicação ocorreu no estádio fenológico $V_{4}$ caracterizado pela presença da terceira folha trifoliada completamente aberta em $50 \%$ das plantas (Fernández et al., 1985). As adubações de cobertura com nitrogênio na forma de ureia foram realizadas em filete contínuo a $10 \mathrm{~cm}$ da linha da cultura sem incorporação e em seguida aplicou-se uma lâmina de água de $15 \mathrm{~mm}$ para o experimento da safra de inverno. Cada subparcela foi formada por 06 linhas de feijão com 5 metros de comprimento, sendo consideradas úteis as 04 linhas centrais, desprezando-se 0,5 metro de cada extremidade.

A temperatura média para a safra das águas foi de $24,9{ }^{\circ} \mathrm{C}$ e a precipitação acumulada de $783 \mathrm{~mm}$, enquanto que para a safra de inverno a temperatura média foi de $21,7{ }^{\circ} \mathrm{C}$ e a precipitação acumulada de 30,4 $\mathrm{mm}$ (Figura 1).
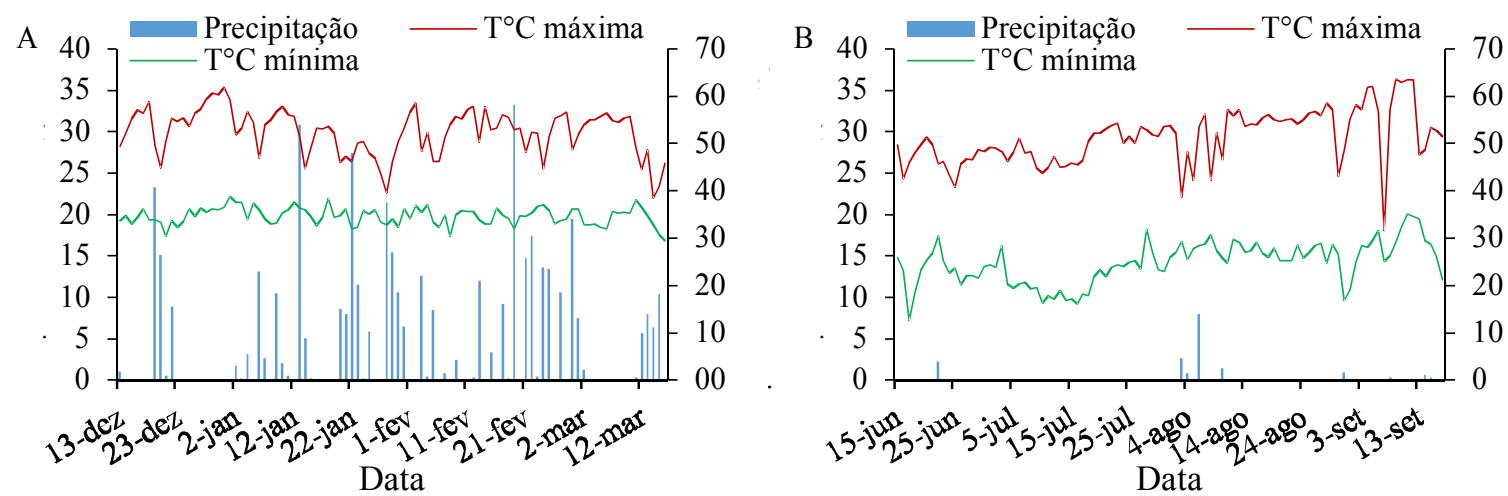

Figura 1. Temperatura máxima, mínima e precipitação diária para a safra das águas $(A)$ e temperatura máxima, mínima e precipitação diária para a safra de inverno (B). 
O controle de plantas daninhas foi realizado por meio químico com uso do herbicida Robust $\left(0,8 \mathrm{~L} \mathrm{ha}^{-1}\right.$ do produto comercial) durante a presença da segunda folha trifoliada completamente aberta. $\mathrm{O}$ controle fitossanitário foi efetuado mediante o monitoramento dos insetos-praga e doenças, utilizando-se pulverizador motorizado e aplicação individual de produtos químicos como Lambda-cialotrina, Abamectina, Azoxystrobin, Monocrotofós, Mancozeb e Tiofanato metílico.

Em ambos os experimentos, as sementes das cultivares de feijoeiro foram tratadas com inseticida (thiamethoxan) e fungicida (carboxin + thiram), nas doses comerciais de $150 \mathrm{~g}$ e $250 \mathrm{ml}$ para cada $100 \mathrm{~kg}$ de sementes, visando o controle de mosca branca (Bemisia spp), cigarrinha verde (Empoasca kraemeri) e doenças como tombamento, podridão radicular e de colo (Fusarium solani, Rhizoctonia solani, Sclerotium rolfsii e Macrophomina phaseolina).

No florescimento pleno $\left(R_{6}\right)$, na área útil de cada parcela, foram retiradas a terceira folha trifoliolada do terço médio de dez plantas de acordo com recomendações de Ambrosano et al. (1997) e determinou-se o teor de nitrogênio, seguindo a metodologia de Bataglia et al. (1983). Para a determinação dos componentes de produção, foram coletadas ao acaso em cada parcela experimental (área útil) 10 plantas para a determinação do número de vagens por planta, número de grãos por vagem e massa de 100 grãos. A produtividade de grãos (PG) foi estimada em função do rendimento de grãos de cada parcela experimental (área útil), padronizando-se a umidade em $0,13 \mathrm{~g} \mathrm{~g}^{-1}$.

As avaliações referentes às características tecnológicas dos grãos foram efetuadas num período de 60 dias após a colheita dos grãos de cada experimento. O teor de proteína dos grãos foi determinado através do seguinte cálculo: $\mathrm{PB}=\mathrm{N}$ total $\times 6,25$ onde: $\mathrm{PB}=$ teor de proteína bruta nos grãos $(\%)$ e $\mathrm{N}$ total $=$ teor de nitrogênio nos grãos, de acordo com a metodologia proposta por Bataglia et al. (1983). O tempo de cozimento dos grãos foi realizada com o auxílio do cozedor de Mattson, descrito por Durigan (1979), que consta basicamente de 25 estiletes verticais terminados em ponta de 1/16". A ponta fica apoiada no grão de feijão durante o cozimento e quando o grão se encontra cozido a ponta penetra-o, deslocando o estilete. $O$ tempo final para cozimento da amostra foi obtido quando $50 \%+1$, ou seja, 13 estiletes, estivessem deslocados. Para essa determinação os grãos ficaram em hidratação em água destilada durante um período mínimo de 12 horas. A relação de hidratação foi determinada pela relação do peso dos grãos de feijão mantidos em água após 12 horas pelo peso inicial $(50 \mathrm{~g})$ colocado para hidratação.

Os dados foram submetidos à análise de variância, ao nível de $5 \%$ de probabilidade (Teste $\mathrm{F}$ ) e, quando significativo, as médias foram comparadas pelo teste de médias de Tukey a $5 \%$ de probabilidade. Quando significativo, o fator doses e a interação doses versus cultivar para a produtividade de grãos foi submetida à análise de regressão polinomial para cada experimento.

\section{Resultados e Discussão}

Avaliou-se o desempenho agronômico e a qualidade dos grãos de cultivares de feijoeiro cultivado na safra das águas (verão) e de inverno em função de doses de nitrogênio em adubação de cobertura.

Para a safra das águas, não foi verificado interação entre cultivar e doses de $\mathrm{N}$ em cobertura para nenhuma variável dos componentes de produção e para a produtividade do feijoeiro (Tabela 1). Ou seja, o padrão de resposta do desempenho agronômico das cultivares em função das doses de $\mathrm{N}$ em cobertura foram semelhantes nessa safra.

Tabela 1. Teor de nitrogênio foliar, componentes de produção e produtividade de grãos de cultivares de feijoeiro-comum sob doses de adubação nitrogenada em cobertura na safra das águas (verão).

\begin{tabular}{|c|c|c|c|c|c|}
\hline Doses de $N\left(\mathrm{~kg} \mathrm{ha}^{-1}\right)$ & $\begin{array}{c}\text { Teor de } \mathrm{N} \text { foliar } \\
\mathrm{g} \mathrm{kg}^{-1}\end{array}$ & $\begin{array}{l}\text { NVP } \\
\mathrm{n}^{\circ} \\
\end{array}$ & $\begin{array}{l}\text { NGV } \\
\mathrm{n}^{\circ}\end{array}$ & $\begin{array}{l}\text { M100 } \\
\text { g } \\
\end{array}$ & $\begin{array}{c}\mathrm{PG} \\
\left(\mathrm{kg} \mathrm{ha}^{-1}\right) \\
\end{array}$ \\
\hline$\overline{0}$ & $60,0 a$ & 7 & 4,4 & 23,6 & 1744 \\
\hline 40 & $56,8 \mathrm{ab}$ & 7,6 & 4,7 & 24,2 & 1801 \\
\hline 80 & $51,5 b$ & 7,8 & 4,8 & 24 & 1841 \\
\hline 120 & $58,1 \mathrm{ab}$ & 7,8 & 4,8 & 23,4 & 1814 \\
\hline 160 & $61,1 \mathrm{a}$ & 7,8 & 4,8 & 23,3 & 1822 \\
\hline $\mathrm{CV}(\%)-\mathrm{D}$ & 11,8 & 9,8 & 8,9 & 4,2 & 6,9 \\
\hline \multicolumn{6}{|l|}{ Cultivares } \\
\hline Pérola & $58,3 a$ & $5,8 \mathrm{~b}$ & $4,2 \mathrm{~b}$ & $25,9 a$ & $1598 \mathrm{~b}$ \\
\hline BRS Pontal & $64,8 a$ & $8,3 a$ & $5,2 a$ & $21,8 \mathrm{c}$ & $1468 \mathrm{c}$ \\
\hline
\end{tabular}




\begin{tabular}{cccccc} 
IPR Juriti & $49,5 \mathrm{~b}$ & $8,8 \mathrm{a}$ & $4,8 \mathrm{a}$ & $23,4 \mathrm{~b}$ & $2349 \mathrm{a}$ \\
\hline CV $(\%)-\mathrm{C}$ & 13,3 & 14,9 & 13,2 & 3,8 & 3,5 \\
\hline Teste F & & & & & \\
Doses de N (D) & $3,7^{*}$ & $2,1 \mathrm{~ns}$ & $2,2 \mathrm{~ns}$ & $2,0 \mathrm{~ns}$ & $1,0 \mathrm{~ns}$ \\
Cultivares (C) & $20,1^{* *}$ & $40,4^{* *}$ & $12,8^{* *}$ & $100,1^{* *}$ & $1113,0^{* *}$ \\
D x C & $1,7 \mathrm{~ns}$ & $1,4 \mathrm{~ns}$ & $0,5 \mathrm{~ns}$ & $0,9 \mathrm{~ns}$ & $1,1 \mathrm{~ns}$
\end{tabular}

NVP: número de vagens por planta; NGV: número de grãos por vagem; M100: massa de cem grãos; PG: produtividade de grãos; CV: coeficiente de variação; ns: não significativo: *Significativo a $5 \%$ de probabilidade; ${ }^{*}$ Significativo a $1 \%$ de probabilidade; Letras maiúsculas iguais na linha e minúsculas na coluna não diferem pelo teste de Tukey $(p>0.05)$.

Além disso, o fator doses de $\mathrm{N}$ foi significativo somente para o teor de $\mathrm{N}$ foliar, enquanto que o fator cultivar foi significativo para todas as variáveis. Isso significa que para a safra das águas a adubação nitrogenada no feijoeiro gera menor variação nos atributos agronômicos da cultura do que o fator genótipo. Comparando cultivares, o genótipo IPR Juriti na safra de verão apresentou PG $47 \%$ e $60 \%$ superior às cultivares Pérola e BRS Pontal, respectivamente.

$\mathrm{Na}$ safra de inverno, o fator dose de $\mathrm{N}$ em cobertura foi significativo para o teor de $\mathrm{N}$ foliar e para a produtividade de grãos do feijoeiro, assim como a interação doses versus cultivar para a PG (Tabela 2). As cultivares com maiores teores de $\mathrm{N}$ foliar foram a Pérola e a BRS Pontal. Entretanto, todos os genótipos apresentaram teores de $\mathrm{N}$ na folha diagnóstica superior ao mínimo estabelecido para o feijoeiro de $30 \mathrm{~g} \mathrm{~kg}^{-1}$ (Ambrosano et al., 1997).

Tabela 2. Teor de nitrogênio foliar, componentes de produção e produtividade de grãos de cultivares de feijoeiro-comum sob doses de adubação nitrogenada em cobertura na safra de inverno.

\begin{tabular}{|c|c|c|c|c|c|c|c|}
\hline \multirow{2}{*}{$\begin{array}{c}\text { Doses de N } \\
\left(\mathrm{kg} \mathrm{h}^{-1}\right)\end{array}$} & \multirow{2}{*}{$\begin{array}{l}\text { Teor de } \mathrm{N} \text { foliar } \\
\mathrm{g} \mathrm{kg}^{-1}\end{array}$} & \multirow{2}{*}{$\begin{array}{l}\text { NVP } \\
n^{\circ}\end{array}$} & \multirow{2}{*}{$\begin{array}{c}\text { NGV } \\
n^{\circ}\end{array}$} & \multirow{2}{*}{$\begin{array}{c}\text { M100 } \\
\text { g }\end{array}$} & \multicolumn{3}{|c|}{$P G\left(\mathrm{~kg} \mathrm{ha}^{-1}\right)$} \\
\hline & & & & & Pérola & Pontal & Juriti \\
\hline 0 & $44,2 \mathrm{~b}$ & 13,4 & 4,6 & 23,6 & $2989 \mathrm{Bab}$ & $2558 \mathrm{Cc}$ & $3556 \mathrm{Aa}$ \\
\hline 40 & $48,7 \mathrm{ab}$ & 13,7 & 4,8 & 23,5 & $3298 \mathrm{ABa}$ & $3112 \mathrm{Bab}$ & $3582 \mathrm{Aa}$ \\
\hline 80 & $48,7 \mathrm{ab}$ & 15,1 & 4,8 & 23,9 & $3362 \mathrm{Aa}$ & $3337 \mathrm{Aa}$ & $3587 \mathrm{Aa}$ \\
\hline 120 & $48,4 \mathrm{ab}$ & 14,4 & 4,6 & 24,4 & $3388 \mathrm{Aa}$ & $2744 \mathrm{Bbc}$ & $3668 \mathrm{Aa}$ \\
\hline \multirow[t]{2}{*}{160} & $52,7 a$ & 13,8 & 4,3 & 23,6 & $2920 \mathrm{Bb}$ & $2688 \mathrm{Bbc}$ & $3340 \mathrm{Aa}$ \\
\hline & 10,6 & 12,4 & 9,4 & 5,9 & \multicolumn{3}{|c|}{6,7} \\
\hline \multicolumn{8}{|l|}{ Cultivares } \\
\hline Pérola & $50,8 a$ & $12,6 \mathrm{~b}$ & $4,4 \mathrm{~b}$ & $25,2 a$ & \multicolumn{3}{|c|}{$3.192 b$} \\
\hline BRS Pontal & 49,7 a & $13,1 \mathrm{~b}$ & $5,3 a$ & $22,6 \mathrm{~b}$ & \multicolumn{3}{|c|}{2887 c } \\
\hline IPR Juriti & $45,0 \mathrm{~b}$ & $16,5 \mathrm{a}$ & $4,2 \mathrm{~b}$ & $23,6 \mathrm{~b}$ & \multicolumn{3}{|c|}{$3547 \mathrm{a}$} \\
\hline & 7,3 & 15,5 & 10,3 & 5,9 & \multicolumn{3}{|c|}{9,1} \\
\hline \multicolumn{8}{|l|}{ Teste F } \\
\hline Doses de N (D) & $4,0^{* *}$ & $1,8 \mathrm{~ns}$ & $2,32 \mathrm{~ns}$ & $0,8 \mathrm{~ns}$ & \multicolumn{3}{|c|}{$9,7^{* *}$} \\
\hline Cultivares (C) & $15,1^{* *}$ & $19,1^{\text {** }}$ & $29,4^{* *}$ & $16,9^{* *}$ & \multicolumn{3}{|c|}{$25,6^{* *}$} \\
\hline$D \times C$ & $1,1 \mathrm{~ns}$ & $0,7 \mathrm{~ns}$ & $0,5 \mathrm{~ns}$ & $0,3 \mathrm{~ns}$ & \multicolumn{3}{|c|}{$2.5^{*}$} \\
\hline
\end{tabular}

NVP: número de vagens por planta; NGV: número de grãos por vagem; M100: massa de cem grãos; PG: produtividade de grãos; CV: coeficiente de variação; ns: não significativo: *Significativo a $5 \%$ de probabilidade; ${ }^{*}$ Significativo a $1 \%$ de probabilidade; Letras maiúsculas iguais na linha e minúsculas na coluna não diferem pelo teste de Tukey $(p>0.05)$

Na média geral da safra de inverno, a cultivar IPR Juriti apresentou produtividade de grãos $11 \%$ e $22 \%$ superior às cultivares Pérola e BRS Pontal, respectivamente. Verifica-se que a PG da cultivar IPR Juriti não foi interferida pelo incremento das doses de $\mathrm{N}$ em cobertura. Entretanto, para as cultivares Pérola e BRS Pontal a produtividade foi incrementada pelo aumento da dose de $\mathrm{N}$ em cobertura até certo limite.

Como a interação doses de $\mathrm{N}$ em cobertura versus cultivar não foi significativa para a PG na safra de verão, verifica-se que na média, as cultivares incrementam sua $P G$ até a dose de $\mathrm{N}$ em cobertura de $108 \mathrm{~kg}$ ha $^{-1}$ (Figura 2A). Ou seja, para a safra de verão a dose de $\mathrm{N}$ em cobertura recomendada para o feijoeiro é próxima de $100 \mathrm{~kg} \mathrm{ha}^{-1}$, dose essa semelhante a recomendada por Ambrosano et al. (1997) de $90 \mathrm{~kg} \mathrm{ha}^{-1}$ de $\mathrm{N}$. Para a safra de inverno, a dose ideal de $\mathrm{N}$ em cobertura foi genótipo-dependente (Figura 2B). A cultivar IPR Juriti não apresentou incremento significativo na PG com o incremento da dose de $\mathrm{N}$ em cobertura. Entretanto, para as cultivares Pérola e BRS Pontal, observou-se que a PG foi incrementada até a dose de $\mathrm{N}$ em cobertura de $79 \mathrm{~kg} \mathrm{ha}^{-1}$ para as duas cultivares. 


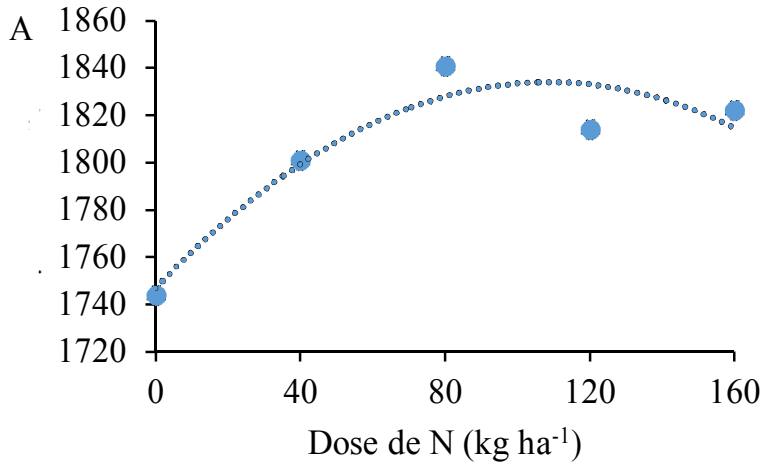

$$
\begin{gathered}
\mathrm{y}=-0.0074 \mathrm{x} 2+1.6011 \mathrm{x}+1747 \\
\mathrm{R}^{2}=0.89
\end{gathered}
$$

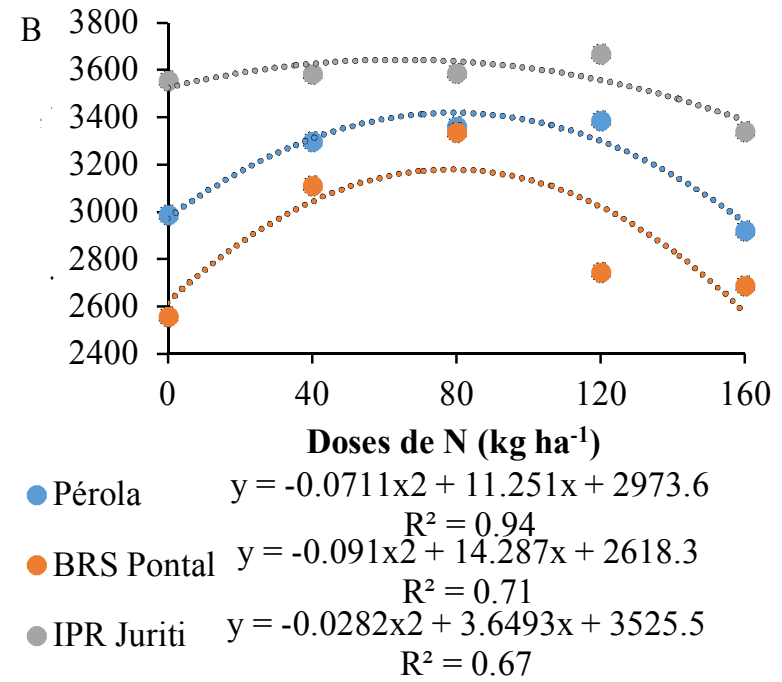

Figura 2. Variação da produtividade do feijoeiro em função das doses de adubação nitrogenada em cobertura para a safra das águas (A) e de inverno (B). PG: produtividade de grãos.

Isso demonstra a necessidade de diferentes manejos agrícolas para a obtenção da máxima PG do feijoeiro e maximização dos recursos quando cultivado em épocas distintas. Na safra das águas (verão), a adubação nitrogenada em cobertura deve ser realizada utilizando como base a quantidade de $\mathrm{N}$ a ser aplicada, que para as condições do presente estudo é próxima de $100 \mathrm{~kg} \mathrm{ha}^{-1}$. Para a safra de inverno, o manejo da adubação nitrogenada deve ser realizada utilizando-se como base a cultivar adotada. Para o caso do presente estudo, por exemplo, não recomenda-se a adubaçao nitrogenada em cobertura para a cultivar IPR Juriti na safra de inverno, pois não há o incremento da PG dessa cultivar com o aumento de doses de $\mathrm{N}$ em cobertura. Para as cultivares Pérola e BRS Pontal, recomenda-se doses de $\mathrm{N}$ em cobertura próximas de $80 \mathrm{~kg} \mathrm{ha}^{-1}$. Assim, obsevando-se a respota de diferentes cultivares em diferentes épocas de semeadura podese recomendar manejos específicos, otimizando a utilização dos recursos.

A PG da safra de inverno foi superior para todas as condições avaliadas em relação à safra das águas, em alguns casos com valores superiores a $100 \%$. Observa-se que dentre os componentes de produção que explicam essa grande variação de PG, pode-se destacar o NVP. Os maiores valores de NVP para a safra de inverno deve-se ao elevado abortamento de flores na safra das águas (verão). Isso ocorre devido às elevadas temperaturas que ocorrem no verão brasileiro, ficando acima da temperatura ideal entre 20 e $25{ }^{\circ} \mathrm{C}$ para a cultura do feijão (Wantanbe, 1953). Assim, na safra de inverno o feijoeiro apresenta maior número de vagens por planta do que na safra das águas, explicando a maior produtividade de grãos nessa safra.

Observou-se que o número de grãos por vagem (NGV) não foi influenciado pela safra, sendo um fator mais interferido pelo genótipo do que por manejos agrícolas (Mingotte et al., 2013). Além disso, a massa de grãos (M100) foi semelhante entre as safras, sendo um componente afetado basicamente quando ocorre déficit hídrico (Cunha et al., 2013), fato que não ocorreu no presente estudo, visto as elevadas precipitações na safra das águas e devido a irrigação na safra de inverno (Figura 1A e 1B).

Além do maior NVP na safra de inverno, outro fator que pode explicar a diferença na produtividade do feijoeiro são fatores bióticos. Verifica-se na literatura que devido à elevada temperatura, umidade relativa do ar e grande período de molhamento foliar, doenças que afetam o feijoeiro são favorecidas na safra de verão (Hallu et al., 2017), afetando diretamente a PG da cultura.

Além disso, outro fator que pode explicar as diferenças de produtividade entre as safras está ligado a fisiologia do feijoeiro. Por ser uma planta C3, a cultura não apresenta mecanismos de concentração de carbono para a realização da fotossíntese (Taiz e Zeiger, 2013). Assim, em elevadas temperaturas a fotossíntese da planta é reduzida e as taxas de fotorrespiração são aumentadas, uma vez que a atividade carboxilase da enzima RubisCO é máxima entre 20 e $22{ }^{\circ} \mathrm{C}$ (Taiz e Zeiger, 2013). Dessa maneira, o cultivo do feijoeiro na safra de inverno apresenta melhores condições para o desenvolvimento da planta.

Quanto ao N foliar, verificou-se que a safra de verão apresentou maiores teores do que na safra de inverno, independentemente da cultivar avaliada. Como o feijoeiro apresenta maior evapotranspiração em períodos mais quentes (Santana et al., 2014), ou seja, na safra de verão, logo maior quantidade de água é 
transpirada pela planta e, consequentemente, maior quantidade de nutrientes é absorvida. Assim, os teores de $\mathrm{N}$ foliar são maiores para épocas com maior transpiração da cultura.

Os maiores teores de $\mathrm{N}$ foliar na safra de verão ajudam a explicar os maiores teores de PB dos grãos para essa safra na maioria dos casos (Tabela 3). Para a safra de verão, observou-se que a cultivar com menor PB foi a Pérola. Entretanto, todos os valores estão acima de $18 \%$, sendo o valor mínimo ideal para o feijoeiro (Farinelli e Lemos, 2010; Pereira et al., 2017). O tempo de cozimento (TC) dos grãos de feijão na safra de inverno apresentou efeito somente de cultivar, sendo o genótipo BRS Pontal com o menor valor. Para a relação de hidratação $(\mathrm{RH})$, as cultivares com maiores valores foram a Pérola e BRS Pontal.

Tabela 3. Qualidade tecnológica dos grãos de feijão em função da adubação nitrogenada em cobertura na safra das águas (verão).

\begin{tabular}{|c|c|c|c|c|c|}
\hline \multirow[t]{2}{*}{ Doses de N $\left(\mathrm{kg} \mathrm{ha}^{-1}\right)$} & \multicolumn{3}{|c|}{$\mathrm{PB}(\%)$} & \multirow{2}{*}{$\begin{array}{l}\mathrm{TC} \\
\text { min }\end{array}$} & \multirow[t]{2}{*}{$\mathrm{RH}$} \\
\hline & Pérola & Pontal & Juriti & & \\
\hline 0 & $31,9 \mathrm{Aa}$ & 29,2 Aba & $27,8 \mathrm{Ba}$ & 30,8 & $1,98 b$ \\
\hline 40 & $30,2 \mathrm{Aab}$ & $27,4 \mathrm{Ba}$ & $25,5 \mathrm{Bbc}$ & 31 & $2,00 \mathrm{a}$ \\
\hline 80 & $30,9 \mathrm{Aab}$ & $29,1 \mathrm{Aa}$ & $24,1 \mathrm{Bc}$ & 31,5 & $1,99 a b$ \\
\hline 120 & $27,8 \mathrm{Ab}$ & $27,9 \mathrm{Aa}$ & $28,2 \mathrm{Aab}$ & 31,8 & $1,98 \mathrm{~b}$ \\
\hline 160 & $32,7 \mathrm{Aa}$ & $30,5 \mathrm{Aa}$ & $31,3 \mathrm{Aa}$ & 31 & $1,98 \mathrm{~b}$ \\
\hline $\mathrm{CV}(\%)-\mathrm{D}$ & & 5,81 & & $10,5^{-}$ & 0,86 \\
\hline \multicolumn{6}{|l|}{ Cultivares } \\
\hline Pérola & & $30,7 a$ & & $31,2 a b$ & $2,03 a$ \\
\hline BRS Pontal & & $28,5 \mathrm{~b}$ & & $30,2 \mathrm{~b}$ & $2,02 \mathrm{a}$ \\
\hline IPR Juriti & & $27,7 \mathrm{~b}$ & & $32,3 \mathrm{a}$ & $1,91 \mathrm{~b}$ \\
\hline $\mathrm{CV}(\%)-\mathrm{C}$ & & 3,62 & & 5,7 & 1,45 \\
\hline \multicolumn{6}{|l|}{ Teste F } \\
\hline Doses de N (D) & & $10,7^{* *}$ & & $0,2 \mathrm{~ns}$ & $5,0^{\star *}$ \\
\hline Cultivares (C) & & $44,3^{* *}$ & & $6,9^{* *}$ & $101,9^{\text {** }}$ \\
\hline$D \times C$ & & $4,0^{* *}$ & & $0,6 n s$ & $1,2 \mathrm{~ns}$ \\
\hline
\end{tabular}

PB: teor de proteína bruta; TC: tempo de cozimento; RH: relação de hidratação; CV: coeficiente de variação; ns: não significativo: *Significativo a $5 \%$ de probabilidade; ${ }^{*}$ Significativo a $1 \%$ de probabilidade; Letras maiúsculas iguais na linha e minúsculas na coluna não diferem pelo teste de Tukey $(p>0.05)$.

$\mathrm{Na}$ safra de inverno, as cultivares que apresentaram maior PB foram a BRS Pontal e a IPR Juriti (Tabela 4). Assim como na safra de verão, os valores de PB na safra de inverno foram superiores ao mínimo ideal para o feijoeiro de 18\% (Farinelli e Lemos, 2010; Pereira et al., 2017). Quanto ao TC, as cultivares BRS Pontal e IPR Juriti apresentaram as menores médias. Para essa característica, observou-se que essas duas cultivares apresentaram menor TC do que quando cultivadas na safra de verão, enquanto que para a cultivar Pérola os valores para o TC foram semelhantes entre as safras. Assim como na safra de verão, a cultivar Pérola apresentou a maior RH na safra de inverno, juntamente com o genótipo BRS Pontal.

Tabela 4. Qualidade tecnológica dos grãos de feijão em função da adubação nitrogenada em cobertura na safra de inverno.

\begin{tabular}{|c|c|c|c|c|c|c|c|}
\hline \multirow[b]{2}{*}{ Doses de N $\left(\mathrm{kg} \mathrm{ha}^{-1}\right)$} & \multicolumn{3}{|c|}{ PB (\%) } & \multicolumn{3}{|c|}{ TC $(\min )$} & \multirow[t]{2}{*}{$\mathrm{RH}$} \\
\hline & Pérola & Pontal & Juriti & Pérola & Pontal & Juriti & \\
\hline 0 & $24,8 \mathrm{Aab}$ & $23,4 \mathrm{Ab}$ & $27,7 \mathrm{Aa}$ & 33,8 Aa & $25,3 \mathrm{Ba}$ & $24,3 \mathrm{Ba}$ & 1,98 \\
\hline 40 & 23,9 Bab & $30,5 \mathrm{Aa}$ & $27,7 \mathrm{ABa}$ & 34,3 Aa & $25,0 \mathrm{Ba}$ & $23,8 \mathrm{Ba}$ & 1,99 \\
\hline 80 & $26,5 \mathrm{Aa}$ & $31,3 \mathrm{Aa}$ & $29,1 \mathrm{Aa}$ & $34,0 \mathrm{Aa}$ & $22,8 \mathrm{Ca}$ & $27,8 \mathrm{Ba}$ & 2,00 \\
\hline 120 & $27,3 \mathrm{Aa}$ & $30,2 \mathrm{Aa}$ & 27,9 Aa & $27,3 \mathrm{Ab}$ & $22,8 \mathrm{Ba}$ & $26 \mathrm{ABa}$ & 1,98 \\
\hline 160 & $20,0 \mathrm{Bb}$ & $30,1 \mathrm{Aa}$ & $28,4 \mathrm{Aa}$ & $26,8 \mathrm{Ab}$ & $21,0 \mathrm{Ba}$ & $25,8 \mathrm{Aa}$ & 1,99 \\
\hline $\mathrm{CV}(\%)-\mathrm{D}$ & & 11,5 & & & 7,9 & & 1,0 \\
\hline \multicolumn{8}{|l|}{ Cultivares } \\
\hline Pérola & & 24,6 b & & & $31,2 a$ & & $2,03 a$ \\
\hline BRS Pontal & & $29,1 \mathrm{a}$ & & & $23,4 \mathrm{~b}$ & & $2,02 \mathrm{a}$ \\
\hline IPR Juriti & & $28,2 \mathrm{a}$ & & & $23,4 \mathrm{~b}$ & & $1,91 \mathrm{~b}$ \\
\hline $\mathrm{CV}(\%)-\mathrm{C}$ & & 8,4 & & & 7,9 & & 1,5 \\
\hline
\end{tabular}


Teste F

Doses de N (D)

Cultivares (C)

$D \times C$
$2,8^{*}$
$22,3^{* *}$
$2,4^{*}$

$7,4^{* *}$

$73,2^{* *}$

$5,6^{\star *}$

$2,7 \mathrm{~ns}$

$110,3^{* *}$

$1,4 \mathrm{~ns}$

PB: teor de proteína bruta; TC: tempo de cozimento; RH: relação de hidratação; CV: coeficiente de variação; ns: não significativo: *Significativo a $5 \%$ de probabilidade; ${ }^{*}$ Significativo a $1 \%$ de probabilidade; Letras maiúsculas iguais na linha e minúsculas na coluna não diferem pelo teste de Tukey $(p>0.05)$.

De acordo com o nível de resistência ao cozimento proposto por Proctor e Watts (1987), na safra de verão todas as cultivares de feijão apresentaram "resistência média ao cozimento", estando na faixa de tempo entre 29 e 32 minutos. Para a safra de inverno, as cultivares BRS Pontal e IPR Juriti, apresentaram "resistência normal" ao cozimento (21 a 28 minutos), enquanto que o genótipo Pérola apresentou "resistência média". Isso indica que na safra de inverno o TC dos genótipos tende a ser inferior à safra de verão. Como a safra de verão apresenta condições mais desfavoráveis para o desenvolvimento do feijoeiro, conforme discutido anteriormente, pode ocorrer nessa safra maior síntese de parede celular e substâncias com maior peso molecular nos grãos que dificultam o rápido cozimento dos mesmos, dificultando a absorção de água pelos grãos (Farinelli e Lemos, 2010).

\section{Conclusões}

O desempenho agronômico e tecnológico das cultivares de feijão é superior na safra de inverno. A cultivar IPR Juriti apresenta desempenho agronômico superior às demais cultivares, independentemente da época de cultivo. A recomendação da dose de nitrogênio em cobertura para a safra das águas independe da cultivar, com valor máximo obtido na dose de $108 \mathrm{~kg} \mathrm{ha}^{-1}$ de $\mathrm{N}$, enquanto que para a safra de inverno a recomendação é genótipo-dependente.

\section{Referências}

Aires, B.C., Soratto, R.P., \& Guidorizzi, F.V.C. (2019). Grain yield and quality of common bean cultivars in response to nitrogen. Científica, 47(2), 231-238. http://dx.doi.org/10.15361/1984-5529.2019v47n2p231-238

Ambrosano, E.J., Wutke, E.B., Bulisani, E.A., \& Cantarella, H. (1997). Feijão. In: Raij, B. V., Cantarella, H., Quaggio, J. A., \& Furlani, A. M. C.(Ed.). Recomendação de adubação e calagem para o Estado de São Paulo. 2.ed. Campinas: IAC, p. 194-195. (Boletim Técnico, 100).

Andrioli, I., \& Centurion, J.F. (1999). Levantamento detalhado dos solos da Faculdade de Ciências Agrárias e Veterinárias de Jaboticabal. In: Congresso Brasileiro de Ciência do Solo, 27, Brasília, 1999. Anais, Brasília, Sociedade Brasileira de Ciência do solo, 32p.

Bataglia, O.C., Furlani, A.M.C., Teixeira, J.P.F., Furlani, P.R.; \& Gallo, J.R. (1983). Métodos de análise química de plantas. Campinas: Instituto Agronômico. 48p. (Boletim Técnico, 78).

Bernardes, T.G., Silveira, P.M., Mesquita, M.A.M., \& Cunha, P.C R. (2014). Resposta do feijoeiro de outonoinverno a fontes e doses de nitrogênio em cobertura. Bioscience Journal, 30(2), 458-468.

CONAB. Companhia Nacional de Abastecimento. (2018). Acompanhamento da safra brasileira: grãos. Décimo Levantamento, v.5, n.10. Julho. Disponível em: < http://www.conab.gov.br/OlalaCMS/uploads/arquivos/17_03_14_15_28_33_boletim_graos_marco_2017bx.pdf $>$ Acesso em 10 set. 2018.

Cunha, P.C., Silveira, P.M.D., Nascimento, J.L.D., \& Alves Júnior, J. (2013). Manejo da irrigação no feijoeiro cultivado em plantio direto. Revista Brasileira de Engenharia Agrícola e Ambiental, 17(7), 735-742. https://doi.org/10.1590/S1415-43662013000700007

Durigan, J.F. (1979). Influência do tempo e das condições de estocagem sobre as propriedades químicas, físico-mecânicas e nutricionais do feijão mulatinho (Phaseolus vulgaris L.). 81f. Dissertação (Mestre em Ciência de Alimentos) Faculdade de Engenharia de Alimentos, Universidade de Campinas, Campinas, 1979.

Farinelli, R., \& Lemos, L.B. (2010). Qualidade nutricional e tecnológica de genótipos de feijão cultivados em diferentes safras agrícolas. Bragantia, 69(3), 759-764. https://doi.org/10.1590/S0006-87052010000300030 
Fernández, F., Gepts, P., \& López, M. (1985). Etapas de dessarollo en la planta del frijol. In: López, M., Fernández, F., \& Schoonhoven, A. V. Frijol: investigación y producción. Cali: CIAT, p.61-78, 1985.

Fischer Filho, J.A., Zocoler, J.L., Poloni, N.M., \& Furlani Júnior, E. (2014). Evapotranspiração e disponibilidade hídrica em feijoeiro (Phaseolus vulgaris) sob estresse hídrico. Revista Brasileira de Agricultura Irrigada, 8(5), 366-374. http://dx.doi.org/10.7127/rbai.v8n500232

Guimarães, R.A.M., Braz, A.J.B.P., Simon, G.A., Ferreira, C.J.B., Braz, G.B.P., \& Silveira, P.M. (2017). Resposta de cultivares de feijoeiro a adubação nitrogenada em diferentes estádios fenológicos. Global Science and Technology, 10(1), 136-148.

Hailu, N., Fininsa, C., Tana, T., \& Mamo, G. (2017). Effects of temperature and moisture on growth of common bean and its resistance reaction against common bacterial blight (Xanthomonas axonopodis pv. phaseoli strains). Journal of Plant Pathology and Microbiology, 8(9), 1000419. http://dx.doi.org/10.4172/2157$\underline{7471.1000419}$

Hungria, M., Nogueira, M.A., \& Araujo, R.S. (2013). Co-inoculation of soybeans and common beans with rhizobia and azospirilla: strategies to improve sustainability. Biology and Fertility of Soils, 49(7), 791-801. http://dx.doi.org/10.1007/s00374-012-0771-5

Leal, F.T., Filla, V.A., Bettiol, J.V.T., Sandrini, F.D.O.T., Mingotte, F.L.C., \& Lemos, L.B. (2019). Use efficiency and responsivity to nitrogen of common bean cultivars. Ciência e Agrotecnologia, 43, e004919. https://doi.org/10.1590/1413-7054201943004919

Mingotte, F.L.C., Guarnieri, C.C.O., Farinelli, R., \& Lemos, L.B. (2013). Desempenho produtivo e qualidade pós-colheita de genótipos de feijão do grupo comercial carioca cultivados na época de inverno-primavera. Bioscience Journal, 29(5), 1101-1110.

Pereira, H.S., Alvares, R.C., Melo, L.C., Costa, A.F.D., \& Carvalho, H.W.L.D. (2017). Culinary and nutritional quality of common bean lines with Carioca grain type and interaction with environments. Revista Ceres, 64(2), 159-166. https://doi.org/10.1590/0034-737X201764020008

Perina, E.F., Carvalho, C.R.L., Chiorato, A.F., Lopes, R.L.T., Gonçalves, J.G.R., \& Carbonell, S.A.M. (2014). Technological quality of common bean grains obtained in different growing seasons. Bragantia, 73(1), 14-22. https://doi.org/10.1590/brag.2014.008

Proctor, J.R., \& Watts, B.M. (1987). Development of a modified Mattson bean cooker procedure based on sensory panel cookability evaluation. Canadian Institute of Food Science and Technology Journal, 20(1), 9-14. https://doi.org/10.1016/S0315-5463(87)70662-2

Raij, B.V., Quaggio, J.A. (1983). Métodos de análise de solo para fins de fertilidade. Campinas: Instituto Agronômico, (Boletim Técnico, 81) p.31.

Sant'Ana, E.V.P., Santos, A.B.D., \& Silveira, P.M.D. (2010). Adubação nitrogenada na produtividade, leitura SPAD e teor de nitrogênio em folhas de feijoeiro. Pesquisa Agropecuária Tropical, 40(4), 491-496. https://doi.org/10.1590/S1983-40632010000400012

Santana, M.J.D., Lemos, L.B., Souza, S.S D., Campos, T.M., Silva, F.M.D., \& Borges, R.D. (2014). Estimated production and evapotranspiration of irrigated bean cultivars. Engenharia Agrícola, 34(6), 1089-1103. https://doi.org/10.1590/S0100-69162014000600006

Santos, A.B.D., \& Fageria, N.K. (2007). Manejo do nitrogênio para eficiência de uso por cultivares de feijoeiro em várzea tropical. Pesquisa Agropecuária Brasileira, 42(9), 1237-1248. https://doi.org/10.1590/S0100204X2007000900004

Taiz, L.; Zeiger, E. (2013). Fisiologia vegetal. 5.ed. Porto Alegre: Artemed. 954p.

Wantanbe, H. (1953). Studies on the unfruitfulness of beans. 3. Influences of temperature on blooming and of relative humidity on the pollen activities of beans. Journal Horticultural Association Japan, 22, 172-176. 